\title{
Integrated docking and enhanced sampling based selection of repurposing drugs for SARS-CoV-2 by targeting host dependent factors
}

Amit Kumawat ${ }^{\ddagger 1,2}$, Sadanandam Namsani ${ }^{\ddagger}, 1$, Debabrata Pramanik ${ }^{\ddagger 2}$, Sudip Roy ${ }^{1, *}$ and Jayant K. $\operatorname{Singh}^{* 1,2}$

${ }^{1}$ Prescience Insilico Private Limited, Old Madras Road, Bangalore 560049, India

${ }^{2}$ Department of Chemical Engineering, Indian Institute of Technology, Kanpur 208016, India

† Same contribution

*Corresponding authors: Sudip Roy (sudip@prescience.in) and Jayant K. Singh

(jayantks@iitk.ac.in)

KEYWORDS

COVID19, molecular dynamics simulation, host proteins, protein-protein interaction, gene regulation, enhanced sampling 


\section{ABSTRACT}

Since the onset of global pandemic, the most focused research currently in progress is the development of vaccine candidates and clinical trials of existing FDA approved drugs for other relevant diseases, in order to repurpose them for the COVID-19. At the same time, several high throughput screenings of drugs have been reported to inhibit the viral components during the early course of infection but with little proven efficacies. Here, we investigate the drug repurposing strategies to counteract the coronavirus infection which involves several potential targetable host proteins involved in viral replication and disease progression. We report the high throughput analysis of literature-derived repurposing drug candidates that can be used to target the genetic regulators known to interact with viral proteins based on experimental and interactome studies. In this work we have performed integrated molecular docking followed by molecular dynamics (MD) simulations and free energy calculations through an expedite insilico process where the number of screened candidates reduces sequentially at every step based on physicochemical information. We elucidate that in addition to the pre-clinical and FDA approved drugs that targets specific regulatory proteins, a range of chemical compounds (Nafamostat, Chloramphenicol, Ponatinib) binds to the other gene transcription and translation regulatory protein with higher affinity and may harbour potential for therapeutic uses. There is a rapid growing interest in the development of combination therapy for COVID19 to target multiple enzymes/pathways. Our insilico approach would be useful in generating leads for experimental screening for rapid drug repurposing against SARS-CoV2 interacting host proteins. 


\section{Introduction}

With currently no vaccine and antiviral drugs available for COVID19 treatment, there is an urgent need for rapid repurposing of drugs for direct therapeutic approaches. ${ }^{1-3}$ This approach takes advantage of existing information for the approved small molecules and biologics and enables rapid clinical trials or regulatory review. Since the onset of the global pandemic, high throughput screening of drugs has been reported to inhibit the viral components during the early course of infection. ${ }^{4-9}$ A large number of drug discovery and repurposing studies are based on the pharmacoepidemiological data available from the coronaviruses family members such as the Middle East Respiratory Syndrome coronavirus (MERS-CoV), the Severe Acute Respiratory Syndrome coronavirus (SARS-CoV-1) and other viruses (Ebola, HIV, Influenza). ${ }^{10-12}$ However, these potential prophylactic measures have certain drawbacks such as strain specific drug resistance and substantial differences in viral protein targets. ${ }^{12,} 13$ Interestingly, targeting host factors is an important strategy in overcoming these restrictions and designing host-directed therapies for treating viral infections. With this inception, several in-vivo and insilico studies have characterised the virus-host interaction networks to functionally annotate multiple host proteins implicated in pathways that promote viral pathogenesis. ${ }^{14-17}$ In particular, Gordon et al., in their recent study, identifies 332 high confidence SARS-CoV2-human protein-protein interactions that aim to understand the hijacking of the host cell during infection. ${ }^{17}$ The interactome reveals several host proteins involved in biological processes such as host genetic regulation, innate immune pathways, vesicle transport and translocation, and provides a comprehensive evaluation of small-molecule candidates for drug repurposing. 


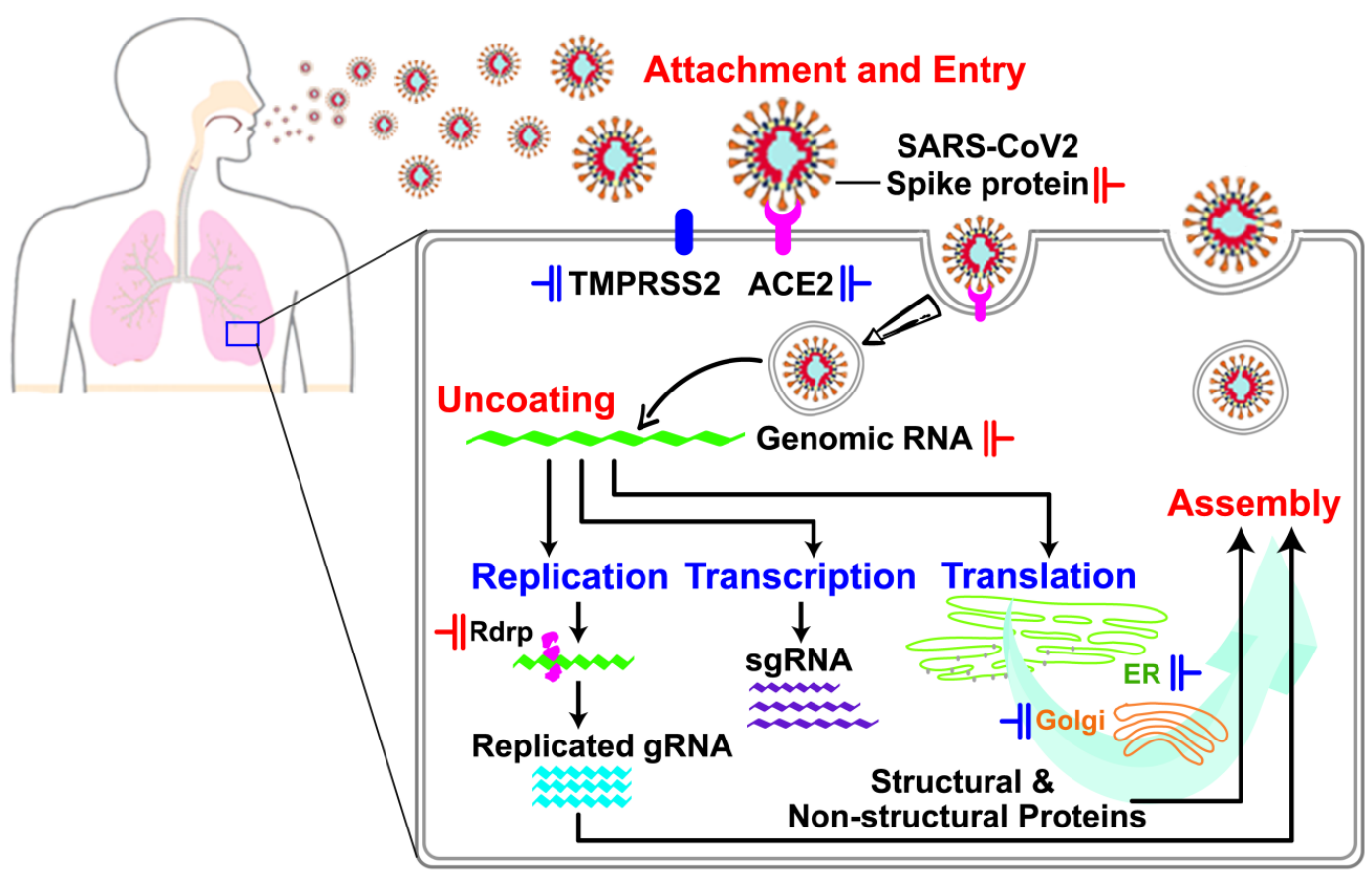

Figure 1. Illustration of therapeutic strategies against COVID-19 through targeting the host and viral proteins as a mechanism for the inhibition of viral transmission. SARS-CoV2 interacts with ACE receptor protein on the cell surface and integrates the virus into the cell. The drug therapy can be targeted at the different host proteins situated in Golgi, ER or gene regulatory pathways involved in the viral replication.

One of the important aspects of viral replication involves the interaction of SARS-CoV-2 with the host machinery. These interactions form a potential target to inhibit SARS-CoV-2 replication and assembly schematically shown in Figure 1. In this work, we demonstrated an insilico robust and novel drug repurposing strategy to counteract the coronavirus infection that involves several potential targetable host proteins involved in viral replication and disease progression. Of all the 66 druggable proteins that are targeted by 69 compounds based on previous interactome studies, ${ }^{17}$ we cluster these proteins into different categories based on the biological and molecular functions. We identify 27 proteins based on UniProt annotations that are involved in host gene regulations and host-viral interactions. These proteins can be targeted by more than 30 
drugs, as suggested by Gordon and coworkers through knowledge-based search and data mining. ${ }^{17}$ Here, we have focused the study on the identification of drugs that can regulate host translation and transcription, and sequentially the viral replication. Host genetic regulatory proteins play an important role in the viral transmission cycle. The viral genome is transcribed or directly translated to produce structural and non-structural (NSPs) proteins necessary to assemble new viral particles. ${ }^{18}$ An extensive work on the host-viral interactome reveals interactions between several key host factors with the viral proteins that facilitate the control of SARS-CoV2 over the mRNA processing and translational machinery. ${ }^{15,17}$ Evidently, these viral mediated alterations in the key genetic regulators can form the primary targets to regulate the polyprotein expression. ${ }^{19}$ Based on the interactome data and the Uniprot annotations for the host proteins, we have shortlisted 13 proteins that constitute the important host genetic regulators (translation and transcription). The proteins were further refined to identify the availability of crystal/cryo-EM structure, binding site information, and structural information for any known drug-bound complex. Out of 13 proteins that are involved in human gene regulation, structural information was available for 9 proteins (Table 1).

Among this list of proteins, the host transcriptional regulator proteins such as Bromo-domain containing proteins (BRD2/BRD4) exhibit antiviral activity upon inhibition through activation of innate immunity pathways. ${ }^{20-22}$ DNA methylation by DNMT1 is another important component of gene regulation. Viral infections identify these DNA methylation patterns to induce endocytosis development. SARS-CoV2 meticulously exploits this epigenetic mechanism for the production of ACE-2 enzyme (virus receptor on the host's lung epithelial cells). ${ }^{23}{ }^{24}$ Interestingly, therapeutic targeting of the host translation machinery (initiation and elongation factors; EF1A1, IF4E, IF4E2) may also prevent viral protein production and inhibit the viral replication. ${ }^{25}$ 
Table 1. Function based classification and selection of host gene regulatory proteins from 332 high confidence host-pathogen protein-protein interactions (PPIs) between SARS-CoV-2 and human proteins based on previous interactome study. ${ }^{17}$ The table highlights the preclinical or FDA approved drugs that target the host proteins and the structural information for these proteins.

\begin{tabular}{|c|l|l|l|l|c|}
\hline INDEX & $\begin{array}{l}\text { Gene } \\
\text { regulation }\end{array}$ & Uniprot & Gene-Name & Article Drugs & $\begin{array}{l}\text { Structure } \\
\text { (PDB ID) }\end{array}$ \\
\hline 1 & BRD2 & P25440 & BRD2_HUMAN & $\begin{array}{l}\text { JQ1, RVX-208, ABBV-744, } \\
\text { CPI-0610, dBET6, MZ1 }\end{array}$ & 3ONI \\
\hline 2 & BRD4 & O60885 & BRD4_HUMAN & $\begin{array}{l}\text { JQ1, RVX-208, ABBV-744, } \\
\text { CPI-0610, dBET6, MZ1 }\end{array}$ & 3MXF \\
\hline 3 & CSNK2A2 & P19784 & CSK22_HUMAN & TMCB, Silmitasertib & 6HMB \\
\hline 4 & DNMT1 & P26358 & DNMT1_HUMAN & Azacitidine, XL413 & 4WXX \\
\hline 5 & EEF1A1 & P68104 & EF1A1_HUMAN & Ternatin-4-(DA3) & 1SYW \\
\hline 6 & EIF4E & P06730 & IF4E_HUMAN & 4E2RCat & IIPC \\
\hline 7 & EIF4E2 & O60573 & IF4E2_HUMAN & Zotatifin-(eFT226) & 2JGB \\
\hline 8 & HDAC2 & Q92769 & HDAC2_HUMAN & Apicidin, Valproic-Acid & 4LY1 \\
\hline 9 & MNK2 & Q9HBH9 & MKNK2_HUMAN & Tomivosertib-(eFT-508) & 6CK6 \\
\hline 10 & MRPS27 & Q92552 & RT27_HUMAN & $\begin{array}{l}\text { Chloramphenicol, Linezolid, } \\
\text { Tigecycline }\end{array}$ & - \\
\hline 11 & EIF4G1 & Q04637 & IF4G1_HUMAN & 4E2RCat & - \\
\hline 12 & EIF4H & Q15056 & IF4H_HUMAN & Zotatifin-(eFT226) & - \\
\hline 13 & LARP1 & Q6PKG0 & LARP1_HUMAN & Rapamycin, Sapanisertib & - \\
\hline 15 & NUP98 & P52948 & NUP98_HUMAN & Verdinexor & - \\
\hline
\end{tabular}

COVID-19 has a triphasic course where the patients undergo a transition from having mild respiratory and systemic symptoms (cold, cough and fever) to hyperinflammation of lung tissues, also referred to as cytokine storm syndrome resulting in acute respiratory syndrome (ARDS) or multiorgan failure. ${ }^{26,27}$ These manifestations namely inflammation, immune dysfunction and 
coagulopathy, often associated with neoplasia, in patients with severe SARS-CoV2 infections give a rationale for the testing of anticancer drugs, ${ }^{28,29}$ and in addition use of immunosuppressive drugs to treat the hyperinflammatory phase of COVID19 that exhibits a high level of cytokines such as IL-6, IL-7 and TNF- $\boldsymbol{\alpha} .^{28-30}$ Hence, several immunosuppressive and anticancer drugs such as tocilizumab, dexamethasone, selinexor, imatinib and sirolimus are being investigated under clinical trials for their possible role toward effective therapy for COVID19. Interestingly, coagulant abnormalities have been observed in patients with severe COVID19 and a range of anticoagulant drugs are being investigated as a part of antithrombotic therapy. ${ }^{29}$ Here, we have performed an extensive insilico drug repurposing exercise for these proteins for a list of selective drugs that are anticancer compounds, anti-coagulants, antibiotics (bacterial infections) or immunosuppressive in nature. Interestingly, we have observed that these drugs are chemically aromatic and heterocyclic nitrogen-containing moieties with a significant number of compounds containing halogen atoms. The inclusion of electron-rich nitrogen or the halogens (predominant for steric effects) in these heterocyclic ring structures favor weak intermolecular interactions with the proteins such as hydrogen bonds, dipole-dipole interactions, hydrophobic effects, van der Waals and $\pi$-stacking interactions that can improve pharmacological features. ${ }^{31-33}$

To understand and screen the drugs that could interact and bind with host proteins, we have assembled an integrated insilico approach consisting of molecular docking followed by molecular dynamics (MD) simulations and enhanced sampling free energy calculations. We followed the protocol designed and applied in our previous work, with some modifications for the identification of antiviral drugs targeting the viral proteins. ${ }^{34}$ Our approach greatly reduces the time and cost of repurposing by insilico identification of lead compounds through an expedited automated process where the number of screened candidates reduces sequentially at 
every step based on physicochemical information. The drug screening process was performed based on multi-protein against multi-drugs approach with very robust free energy calculations from enhanced sampling. Prior studies have attempted to repurpose drugs that are implicated in similar diseases such as cancers, rheumatoid disorders and blood coagulation disorders. ${ }^{29} \mathrm{We}$ examined the physical nature (polar/non-polar) of interactions between the binding site of the proteins and drugs using molecular docking studies. Based on the initial findings, several candidate drugs exhibit higher docking binding energy and hydrogen bonded interactions as compared to the control protein-drug complex. However, virtual screening tools like molecular docking are known to introduce inaccuracies in the binding predictions due to the lack of sampling and exclusion of various factors such as protein dynamics and solvent electrostatics. Our high throughput analysis that includes free energy barrier calculations predicts various compounds (FDA-approved or clinically approved) that complements the earlier works in the drug repurposing strategies for COVID19.

\section{Materials and methods}

\section{Rapid Drug repurposing Protocol}

At first, molecular docking has been used to study the binding affinities for the drugs and host transcriptional regulator proteins. The molecular docking also provides a reasonable well minimized conformation and binding pose for initiating a molecular dynamics (MD) simulation. Further, the stability of the obtained docked poses has been evaluated using MD simulations. MD simulations provide the interaction energies and the stability of the drugs at the binding site of the protein. After MD simulations, the drugs with significant interactions based on hydrogen bonding and non-bonded interactions with the binding sites of the target proteins have been 
selected for well-tempered metadynamics (wt-metaD) simulations. The binding free energy for each drug with the target proteins calculated from wt-metaD and enhanced sampling of drugs at the binding site deterministically indicates the best possible repurposing drugs. Further, we have analysed all the trajectories from MD and wt-metaD to understand specific interactions between the drugs and residues at the binding sites. Additionally, we have calculated the drugs' residence time at the binding site using the wt-metaD simulations trajectories.

\section{Molecular modelling and docking}

The Autodock suite (Autodock 4.2.6) was used to perform molecular docking analysis of the compounds for different proteins as the docking targets. ${ }^{35}$ The docking was performed onto the available crystal structures for different proteins. The missing loop regions in the selective proteins were modelled using Modeller (Modeller 9.24). ${ }^{36}$ The docking sites were identified based on either availability of inhibitor-bound crystal structures or ligand site prediction using the Autoligand tool in the Autodock suite. ${ }^{37}$ The protein structures and chemical compounds were energy minimised before docking analysis. To perform the docking of the compounds onto the identified ligand binding sites, grid-based ligand docking was performed. Ligand centered grid maps were generated using the Autogrid program with a spacing of $0.375 \AA$ and grid dimensions of $60 \times 60 \times 60 \AA^{3}$. The best-docked structures were identified based on the docking energy and population distribution of the lowest-energy clusters from the conformational clustering histogram in Autodock.

\section{Molecular Dynamics Simulations}

We have performed molecular dynamics simulations for different protein-ligand complexes using GROMACS-2018. ${ }^{38}$ The best-docked ligand conformations for different systems were 
selected as the starting structure for the simulations. In addition, the simulations were also performed for selective protein-ligand crystal structures as control systems, where the ligand can differ from the list of screening compounds. The charmm27 force field with cmap corrections was used for the proteins. ${ }^{39}$ The geometry optimizations of all the ligands (Table S1) were performed using a semi-empirical method at the PM6 level, followed by geometry optimization using density functional theory (DFT) with the M06 functional and 6-311g (d,p) basis set. To account for the bulk solvent effects, the PCM method is used. Further, the partial atomic charges for the ligands are computed by fitting the electrostatic potential using the CHELPG method as implemented in the Gaussian09 code. These charges are computed for the optimized structures using a single point calculation at the DFT with the M06 functional with 6-311g (d,p) basis set and used water as the solvent. The forcefield parameters for ligand molecules were obtained using swissparam webservice which performs automated assignment of parameters by analogy and is compatible with charmm force field. ${ }^{40}$ All the structures were solvated using the TIP3P water model and simulated with periodic boundary conditions. The systems were neutralized by adding counter ions, $\mathrm{Na}+$ in the negatively charged system and $\mathrm{Cl}^{-}$in the positively charged system. The structures were energy minimized using steepest descent algorithm. This was followed by NVT equilibration using modified Berendsen thermostat ${ }^{41}$ and NPT equilibration using Parrinello-Rahman barostat. ${ }^{42}$ For the production run, the temperature was controlled through velocity rescaling at $300 \mathrm{~K}$ with a time constant of $0.1 \mathrm{ps}$ and pressure was kept constant at 1 bar. The cutoff for short-range interactions was $1.0 \mathrm{~nm}$, and the long-range electrostatic interactions were calculated using Particle-Mesh Ewald (PME) method. ${ }^{43}$ The bonds were constrained using the LINCS algorithm. ${ }^{44}$ We have performed equilibrium MD simulations of these systems for 1 ns to obtain energetically favourable protein-ligand conformations post rigid 
docking protocol. The non-bonded interaction energies and hydrogen bond analysis were performed using the in-built GROMACS utilities.

\section{Metadynamics simulations}

Further, we have performed free energy calculations using enhanced sampling based technique metadynamics and its variant well-tempered metadynamics. ${ }^{45}$ We have used software packages PLUMED 2.5.4 combined with GROMACS 2018 as the MD engine. ${ }^{46}$ We have taken the final coordinates from the equilibrium MD simulations as the initial starting conformations for metadynamics simulations. Since the dissociation event of a ligand from the binding pocket of a protein takes sufficiently long time, and this process is separated by high energy barriers, so unbiased brute force MD simulations would not be sufficient to observe dissociation events within a short simulation time. Thus, to make the dissociation process faster and to study these kind of complex systems, external bias is added to the system which accelerates the dissociation processes. Thus using enhanced biased sampling, we study protein-ligand systems using available limited resources and within a short time. To address the length and time scale issues for complex biomolecular systems, various methods have been developed over the years to calculate free energies for these systems of interest. From these huge lists of enhanced sampling techniques, we used metadynamics (metaD) and its variant well-tempered metadynamics (wtmetaD). The reaction coordinate (s) is a linear or non-linear combination of the few selected order parameters of the systems which are functions of the coordinates of the system. Here, we choose distance (d) between the center of mass - center of mass of the ligand heavy atoms and protein binding pocket as the reaction coordinate for biasing in the simulations. We add a gaussian bias and once the system converges we can extract the unbiased Boltzmann probability of the distribution of RC by adding up the deposited hills over the course of the simulation. In 
the wt-metaD simulations, the Gaussian hills were deposited at every 500 steps (1ps), with hill height in the range of $1.5-2.0 \mathrm{~kJ} / \mathrm{mol}$, width $0.02-0.1 \mathrm{~nm}$, biasfactor $10-15$, and temperature at 300K. For each ligand-protein system, we performed minimum 10 independent runs starting from different initial coordinates and velocities for each copy and then averaged over probabilities to get the averaged free energy.

Further to support the discernment of ligand-protein binding nature, ligand residence time is estimated using the wt-metaD simulations data. The residence time (RT) of a ligand within a free energy basin can be estimated using the equation 1:

$$
R T_{\text {calc }}=\alpha(t) \times t
$$

In the above equation $t$ is the wt-metaD simulation time required to observe the transition from free energy basin A to basin B and $\alpha(t)$ is the acceleration factor which is defined using the equation 2.

$$
\alpha(t)=\frac{1}{t} \int_{0}^{t} e^{\beta V\left(s(R), t^{\prime}\right)} d t^{\prime}
$$

where the $\alpha(t)$ is running average of the bias applied over the metadynamics run within in the time $\mathrm{t}, V\left(s(R), t^{\prime}\right)$ is the bias at time $\mathrm{t}$ in the metadynamics simulation and $\beta$ is the Boltzmann factor. The simulation time necessary for the transition from the energy basin, $t$, is determined from the derivative of $\alpha(t)$ versus t plot.

$$
\frac{d \propto}{d t}=\frac{1}{t}\left[e^{\beta V(s, t)}-\frac{1}{t} \int_{0}^{t} e^{\beta V\left(s(R), t^{\prime}\right)} d t^{\prime}\right]
$$


The derivative exhibits abrupt change whenever the ligand crosses an energy barrier and goes into a new state. The sign change is used to identify the transition time (Figure S1), which is required to calculate the residence using equation 1 . This transition time is used to get the drug residence time.

\section{Results and discussion}

\section{Structure selection and binding site determination}

The dependence of virus on the host translational machinery has introduced constraints that are central to the viral biology and has led to an alternative and complementary strategy to target the host factors essential for viral replication. Translation factors play a critical role in protein synthesis, and dysregulation of their activity have been implicated in a broad range of disorders, including cancers, cell transformations, etc. Several small-molecule inhibitors have been proposed as therapeutic potential, and few are clinically approved that exhibit antitumor activity and modulate gene expression. Hence, several crystal structures of gene regulation proteins (eIF, kinases, histone deacetylases) with the inhibitors have been reported. The potential ligandbinding site in the target protein is the prerequisite and critical information for any drug repurposing strategy. Our approach is to computationally screen drugs based on the inhibitor binding site information obtained from the existing protein-drug crystal structures.

We have selected the crystal structures for proteins in the inhibitor bound state from the protein data bank. The preferential criterion for the selection was to identify the protein structures cocrystallised with drugs that are suggested for repurposing through an extensive literature and knowledge-based search. ${ }^{17}$ Interestingly, we could find structures for Casein kinase 2 (CSK22), MAP kinase 2 (MNK2) and bromodomains (BRD2/BRD4) proteins in complex with 
Silmitasertib, Tomivosertib and JQ1 respectively (PDB: 6HMB, 2AC3, 3ONI, 3MXF). The ligand binding sites for histone deacetylase (HDAC2), translation initiation factor eIF4E were obtained based on co-crystal structures with inhibitors (PDB: 4LY1, 1IPC2). These inhibitor bound structures were used as a control set for further analysis. We have also used the AutoLigand tool ${ }^{37}$ to predict the binding site in the translation factors (EF1A1 and eIF4E2) and DNA methyltransferase 1 (DNMT1). Two ligand binding sites were predicted for EF1A1 (PDB: 1SYW) and one site for eIF4E2 (PDB: 2JGB). Further, two ligand binding sites were defined for DNMT1 based on the ligand bound crystal structure (PDB: 3SWR) and zinc finger region based on the function annotation from UniProt. These sites were further analysed to understand the electrostatic nature of the binding cavity before proceeding with the molecular docking protocol (Figure S2). Several of these binding sites in proteins (HDAC2, MNK2, DNMT1) exist as deep concave pockets that maximise the protein-ligand interactions. The core of the binding cavity consists of hydrophobic residues or polar residues that could positively contribute to the binding of organic or charged molecules. Similarly, there are binding sites (eIF4E, EF1A1) that are relatively flat protein surfaces consisting of both polar and apolar residues.

\section{Molecular docking and MD simulation}

Of the several insilico approaches that aim at identifying an existing drug for targeting clinically relevant targets, molecular docking has proven to be a powerful tool and could be reliably used for starting structure generation for MD. Docking of all the 12 binding sites corresponding to 9 proteins (Table 1) has been carried out with 28 drugs (Table S1). These drugs were derived from the suggested list of drugs using interactome studies for proteins involved in gene regulation. In addition, we have also included drugs that target the known protein-viral interactions based on UniProt functional annotations. The docking was performed using Autodock software, and the 
docking energy for the most populated cluster of docked structures was determined for more than 250 protein-drug combinations. Figure $2 \mathrm{a}$ shows the heat map representation of these docking energies. We have observed that the docking energy difference between the best-docked conformations for different protein-drug complexes is less than $1 \mathrm{kcal} / \mathrm{mol}$. However, the molecular docking protocol incorporates only the static interactions excluding the effect of solvent and ions in the system, and thus it does not count the entropic effect. It is very well established that thermodynamics and conformational dynamics play crucial roles in the interaction and stability of the protein-ligand systems. Hence, the docking protocol was followed by MD simulations of ligand-docked structures.

MD simulations were performed for all the best-docked structures of protein-drug complexes to equilibrate the systems. These would allow the conformational fluctuations of the drug inside the binding cavity and subsequent interactions with the protein residues at the binding site. We have analysed the hydrogen bonding interactions and the non-bonded interaction energies for all the complexes. The non-bonded interaction energies for the protein-drug complex has been shown in Figure $2 b$ in the form of a heatmap. It can be observed that few drugs have higher interaction energy as compared to the other drugs for individual proteins (Table S2). It is evident that the interaction energies for the complexes vary from $-90 \mathrm{kcal} / \mathrm{mol}$ to $-10 \mathrm{kcal} / \mathrm{mol}$. The large difference in the electrostatic and van der Waals interaction energies between the systems is accounted for based on additional favourable polar and nonpolar interactions that vary with the chemical nature of the drug itself. To understand these differences in the energies, we have also analysed the hydrogen bonding sites of drugs in each protein. In certain cases, the given set of drugs exhibit common hydrogen bonding residues in the binding site of a particular protein. For example, K69, H161, D176 in CSK22; Y386, N429 in BRD2; Y97, M105, N140 in BRD4 and 
so on (See Table S2 for list of hydrogen bonding residues for each protein-drug complex). Thus, it is evident from our analysis that multiple drugs can target the binding site with varying degrees of interactions. Several of these drugs are FDA approved genetic translation regulators and have favourable pharmacological properties. Thus, these drugs can be promising candidates for repurposing for treating COVID-19 patients in phase 2-3 of the disease.

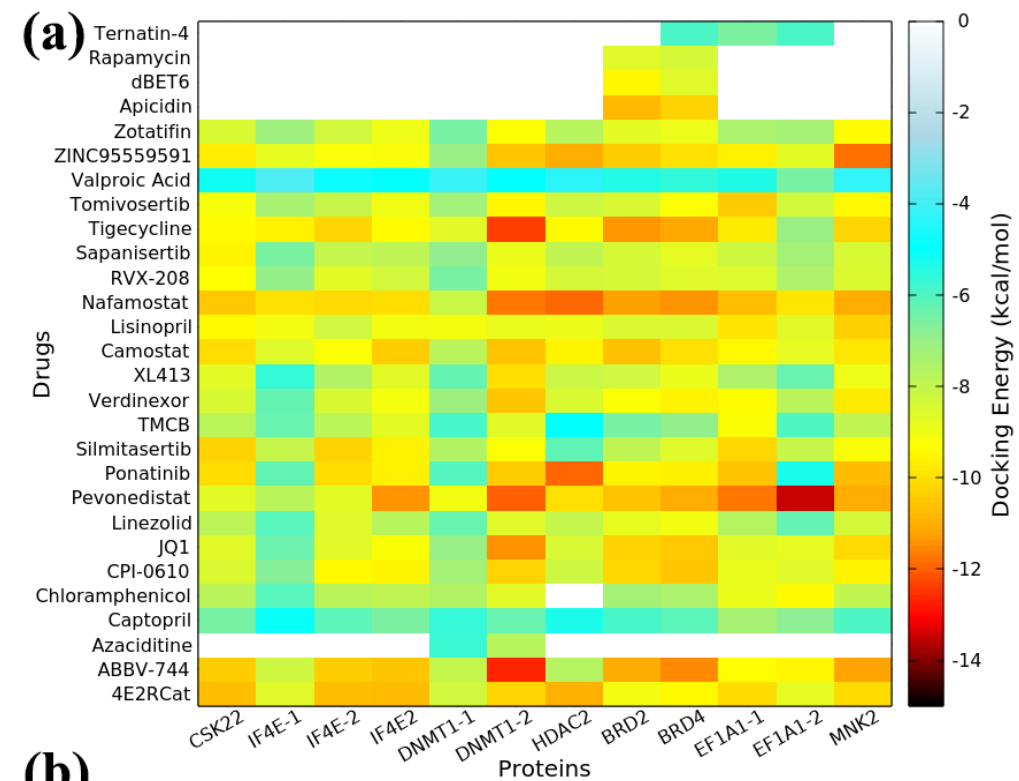

(b)

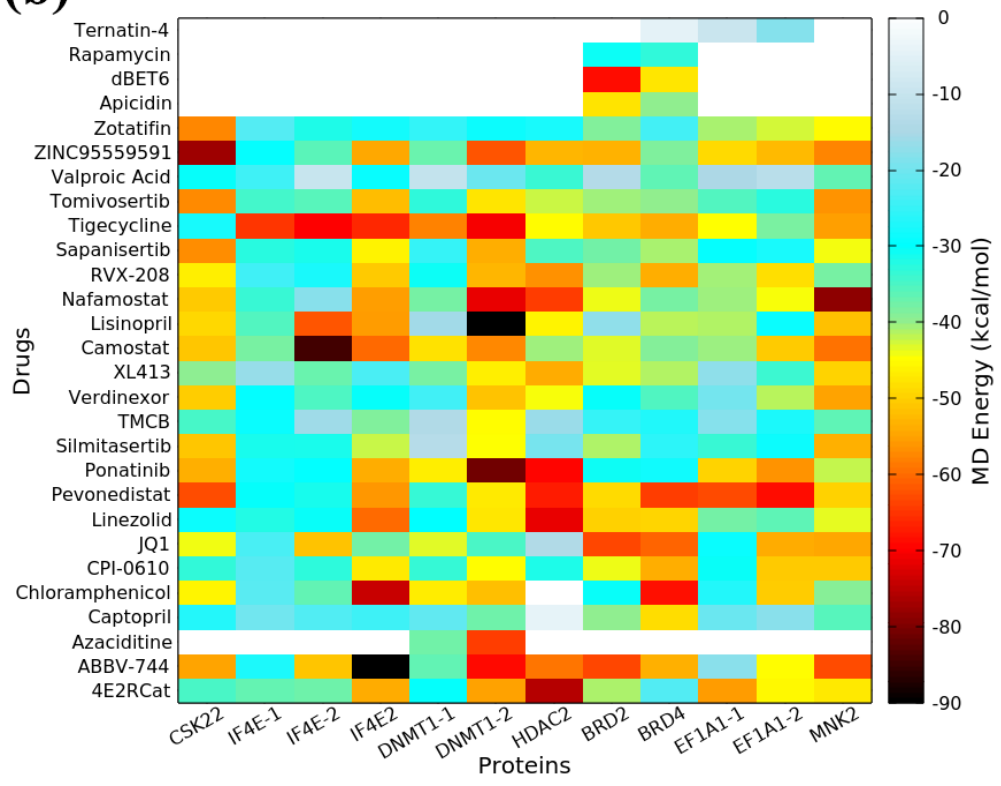

Figure 2. Heat map representation of electrostatic interaction energies from (a) molecular docking and (b) MD simulation. 
Further, to quantitatively estimate the binding affinity of these drugs, we calculated the dissociation free energy for these protein-drugs from free energy calculations. Interestingly, we find that not all drugs show high/similar binding affinity toward a protein in our preliminary analysis. Hence, we have reduced the number of calculations through the selection of a set of drugs for each protein for free energy calculations. The protein-drugs systems were ranked on the basis of docking energy, non-bonded interaction energies and the hydrogen bonds. The cutoff for each protein was chosen in such a way that the energetics exhibit the electrostatic or hydrophobic complementarity between the binding site of the protein and drugs (Table S2). For example, the van der Waals interaction energy dominates the electrostatic interaction energy for the HDAC2 protein and accounts for the top ranked protein-drugs with respect to docking energy. Similarly, the ranking was performed for all the systems, including the control set of drugs. This exercise reduces the large number of protein-drug combinations that ranked low and have lower interaction energy than the drugs with higher interactions.

\section{Quantitative binding estimation}

Following the above selection criterion, we have selected a list of protein-drug combinations shown in Table S1, and for those corresponding combinations, the instantaneous snapshots from the short equilibrium MD simulations are shown in Figure S3. We have calculated the average free energy barriers for these protein-drug combinations. To calculate the average FESs, we first calculated the probability from independent free energy simulations and then calculated the averaged probability and average FES. The FES barriers are shown in Figure S4. We extracted the FES barriers corresponding to all the drugs for respective proteins and for multiple binding sites for a single protein. Table 2 shows the FES barrier heights for all the selected protein-drugs with respective errors in the calculations. We calculated the barrier heights by subtracting the 
maximum of the FES value from the global minimum in the FES profile. To understand these quantitative values better, we have plotted these barrier heights in Figure 3 in the heatmap representation. Figure 3 shows the heat map representation for the free energy barriers and compared our results with that obtained from the heat map shown in Figure 2.

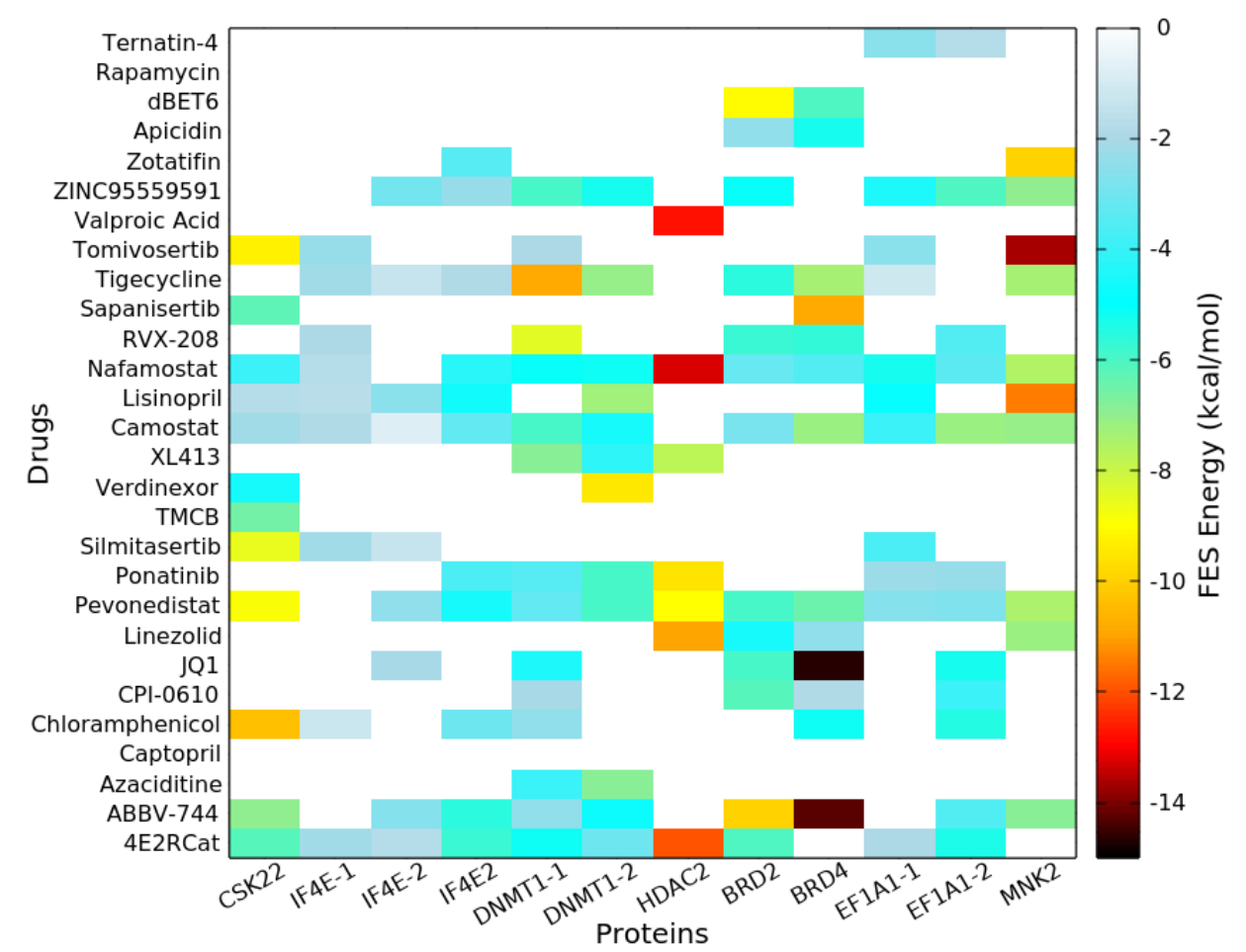

Figure 3. Heat map representation of the free energy barrier for different protein-drug combinations from metadynamics simulations.

The color bar ranges from $-15 \mathrm{kcal} / \mathrm{mol}$ to $0 \mathrm{kcal} / \mathrm{mol}$, as shown on the right side color bar. Interestingly, we find that the drugs with higher binding energy barriers for different proteins include control (crystal structure bound inhibitor, e.g., Tomivosertib in MNK2, Silmitasertib in CSK22) among the top scoring drugs. We must also note that our approach that identifies repurposing drugs with higher binding energy corroborates the known experimental findings with respect to approved or under clinical trial drugs for specific proteins (Valproic Acid in HDAC2, 4E2RCat in eIF4E). 
Table 2. FES barrier heights and the estimated residence times for all the protein-drug systems.

\begin{tabular}{|c|c|c|c|c|c|c|c|}
\hline & Ligand & $\begin{array}{c}\Delta G \\
(\mathrm{kcal} / \mathrm{mol})\end{array}$ & $\begin{array}{l}\text { Residence } \\
\text { time (min) }\end{array}$ & & Ligand & $\begin{array}{c}\Delta G \\
\text { (kcal/mol) }\end{array}$ & $\begin{array}{l}\text { Residence } \\
\text { time (min) }\end{array}$ \\
\hline \multirow{13}{*}{$\frac{\widehat{a}}{n}$} & dBET6 (L12) & $-9.1(0.50)$ & $2.5 \mathrm{E}+13$ & \multirow{13}{*}{$\frac{\overrightarrow{0}}{\frac{1}{n}}$} & dBET6 (L12) & $-6.1(0.27)$ & $1.2 \mathrm{E}+04$ \\
\hline & ABBV-744 (L11) & $-10.0(0.46)$ & $4.0 \mathrm{E}+07$ & & ABBV-744 (L11) & $-14.3(0.40)$ & $2.0 \mathrm{E}+10$ \\
\hline & CPI-0610 (L13) & $-6.2(0.45)$ & $2.4 \mathrm{E}+00$ & & CPI-0610 (L13) & $-1.9(0.38)$ & $8.9 \mathrm{E}+00$ \\
\hline & RVX-208 (L2) & $-5.8(0.55)$ & $2.1 \mathrm{E}+04$ & & RVX-208 (L2) & $-5.7(0.29)$ & $4.7 \mathrm{E}+06$ \\
\hline & JQ1 (L1) & $-6.0(0.42)$ & $1.4 \mathrm{E}+03$ & & JQ1 (L1) & $-14.7(0.54)$ & $1.2 \mathrm{E}+17$ \\
\hline & ZINC95559591 (L10) & $-5.1(0.29)$ & $1.7 \mathrm{E}+06$ & & Pevonedistat (L17) & $-6.5(0.37)$ & $1.1 \mathrm{E}+16$ \\
\hline & Tigecycline (L26) & $-5.6(0.32)$ & $3.7 \mathrm{E}+05$ & & Tigecycline (L26) & $-7.4(0.53)$ & $2.1 \mathrm{E}+06$ \\
\hline & Linezolid (L27) & $-4.6(0.28)$ & $3.8 \mathrm{E}+02$ & & Nafamostat (L24) & $-3.6(0.48)$ & $4.2 \mathrm{E}+09$ \\
\hline & Pevonedistat (L17) & $-6.0(0.44)$ & $1.4 \mathrm{E}+03$ & & Linezolid (L27) & $-2.5(0.38)$ & $4.4 \mathrm{E}+05$ \\
\hline & Apicidin (L5) & $-2.5(0.42)$ & $4.6 \mathrm{E}+01$ & & Apicidin (L5) & $-5.3(0.37)$ & $4.1 \mathrm{E}+05$ \\
\hline & Nafamostat (L24) & $-3.2(0.35)$ & $9.6 \mathrm{E}+00$ & & Chloramphenicol (L25) & $-5.2(0.29)$ & $3.8 \mathrm{E}+03$ \\
\hline & Camostat (L23) & $-2.9(0.49)$ & $1.4 \mathrm{E}+06$ & & Camostat (L23) & $-7.2(0.45)$ & $2.4 \mathrm{E}+07$ \\
\hline & 4E2RCat (L19) & $-6.1(0.34)$ & $2.2 \mathrm{E}-01$ & & Sapanisertib (L14) & $-10.9(0.42)$ & $1.4 \mathrm{E}+10$ \\
\hline \multirow{10}{*}{ 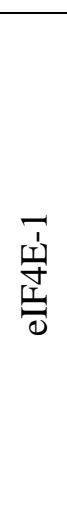 } & 4E2RCat (L19) & $-2.2(0.38)$ & $1.2 \mathrm{E}+01$ & \multirow{10}{*}{ 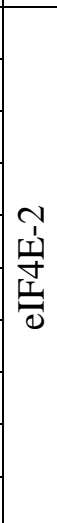 } & 4E2RCat (L19) & $-1.8(0.28)$ & $1.2 \mathrm{E}-03$ \\
\hline & 4TPW-33R & $-1.0(0.29)$ & $1.2 \mathrm{E}+01$ & & Camostat (L23) & $-0.84(0.22)$ & $1.1 \mathrm{E}-03$ \\
\hline & Tigecycline (L26) & $-2.2(0.30)$ & $1.7 \mathrm{E}+00$ & & Tigecycline (L26) & $-1.4(0.40)$ & $1.8 \mathrm{E}+02$ \\
\hline & Camostat (L23) & $-1.9(0.22)$ & $1.7 \mathrm{E}-03$ & & Lisinopril (L22) & $-2.6(0.28)$ & $5.7 \mathrm{E}+00$ \\
\hline & Lisinopril (L22) & $-1.7(0.26)$ & $1.4 \mathrm{E}-03$ & & JQ1 (L1) & $-2.1(0.24)$ & $5.2 \mathrm{E}+00$ \\
\hline & Tomivosertib (L20) & $-2.4(0.42)$ & $8.7 \mathrm{E}+00$ & & ABBV-744 (L11) & $-2.7(0.29)$ & $3.6 \mathrm{E}+00$ \\
\hline & Nafamostat (L24) & $-1.8(0.25)$ & $1.0 \mathrm{E}+01$ & & ZINC95559591 (L10) & $-3.0(0.31)$ & $1.1 \mathrm{E}-01$ \\
\hline & Silmitasertib (L3) & $-2.2(0.25)$ & $4.4 \mathrm{E}-02$ & & Pevonedistat (L17) & $-2.5(0.30)$ & $7.9 \mathrm{E}+01$ \\
\hline & RVX-208 (L2) & $-2.0(0.22)$ & $1.3 \mathrm{E}+01$ & & Silmitasertib (L3) & $-1.4(0.32)$ & $1.2 \mathrm{E}-02$ \\
\hline & Chloramphenicol (L25) & $-1.3(0.26)$ & $3.4 \mathrm{E}-06$ & & & & \\
\hline \multirow{12}{*}{$\frac{\vec{I}}{\frac{1}{I I}}$} & Ternatin-4 (L18) & $-2.6(0.37)$ & $5.1 \mathrm{E}+04$ & \multirow{12}{*}{$\frac{\frac{T}{1}}{\frac{\pi}{L}}$} & Ternatin-4 (L18) & $-1.8(0.49)$ & $2.7 \mathrm{E}-006$ \\
\hline & Pevonedistat (L17) & $-2.7(0.25)$ & $1.0 \mathrm{E}+05$ & & Pevonedistat (L17) & $-2.8(0.55)$ & $3.9 \mathrm{E}+04$ \\
\hline & 4E2RCat (L19) & $-2.0(0.37)$ & $5.4 \mathrm{E}+02$ & & JQ1 (L1) & $-5.3(0.34)$ & $1.1 \mathrm{E}-01$ \\
\hline & Ponatinib (L7) & $-2.3(0.26)$ & $8.6 \mathrm{E}+09$ & & ZINC95559591 (L10) & $-6.1(0.27)$ & $3.8 \mathrm{E}+05$ \\
\hline & Nafamostat (L24) & $-5.3(0.41)$ & $3.8 \mathrm{E}+13$ & & Chloramphenicol (L25) & $-5.5(0.41)$ & $3.9 \mathrm{E}+02$ \\
\hline & Lisinopril (L22) & $-4.9(0.35)$ & $9.3 \mathrm{E}+00$ & & Camostat (L23) & $-7.2(0.46)$ & $8.3 \mathrm{E}+02$ \\
\hline & Tigecycline (L26) & $-1.2(0.29)$ & $5.4 \mathrm{E}+01$ & & ABBV-744 (L11) & $-3.6(0.23)$ & $3.6 \mathrm{E}-04$ \\
\hline & ZINC95559591 (L10) & $-4.5(0.52)$ & $1.4 \mathrm{E}+08$ & & Nafamostat (L24) & $-3.4(0.24)$ & $7.1 \mathrm{E}+00$ \\
\hline & Camostat (L23) & $-4.0(0.55)$ & $8.8 \mathrm{E}+08$ & & 4E2RCat (L19) & $-5.4(0.34)$ & $1.44 \mathrm{E}+02$ \\
\hline & Tomivosertib (L20) & $-2.6(0.35)$ & $1.4 \mathrm{E}-03$ & & CPI-0610 (L13) & $-4.0(0.53)$ & $2.5 \mathrm{E}+02$ \\
\hline & Silmitasertib (L3) & $-3.7(0.28)$ & $3.3 \mathrm{E}-01$ & & Ponatinib (L7) & $-2.4(0.33)$ & $6.2 \mathrm{E}+03$ \\
\hline & & & & & RVX-208 (L2) & $-3.6(0.28)$ & $9.4 \mathrm{E}-02$ \\
\hline \multirow{3}{*}{$\frac{\widetilde{N}}{\tilde{U}}$} & Silmitasertib (L3) & $-8.6(0.56)$ & $1.3 \mathrm{E}+09$ & \multirow{3}{*}{ 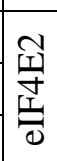 } & Zotatifin (L16) & $-3.5(0.31)$ & $1.8 \mathrm{E}-01$ \\
\hline & Pevonedistat (L17) & $-8.9(0.54)$ & $8.4 \mathrm{E}+05$ & & ABBV-744 (L11) & $-5.6(0.55)$ & $1.1 \mathrm{E}+12$ \\
\hline & ABBV-744 (L11) & $-7.0(0.41)$ & $1.7 \mathrm{E}+06$ & & Pevonedistat (L17) & $-4.6(0.37)$ & $1.4 \mathrm{E}+11$ \\
\hline
\end{tabular}




\begin{tabular}{|c|c|c|c|c|c|c|c|}
\hline & Verdinexor (L28) & $-4.6(0.39)$ & $3.7 \mathrm{E}+02$ & & Camostat (L23) & $-3.3(0.34)$ & $7.91 \mathrm{E}+01$ \\
\hline & Chloramphenicol (L25) & $-10.4(0.50)$ & $4.1 \mathrm{E}+02$ & & Tigecycline (L26) & $-1.9(0.46)$ & $4.1 \mathrm{E}+02$ \\
\hline & 4E2RCat (L19) & $-6.2(0.31)$ & $9.1 \mathrm{E}+07$ & & 4E2RCat (L19) & $-5.8(0.28)$ & $1.7 \mathrm{E}+02$ \\
\hline & TMCB (L4) & $-6.6(0.55)$ & $1.3 \mathrm{E}+03$ & & Nafamostat (L24) & $-4.3(0.31)$ & $7.5 \mathrm{E}+03$ \\
\hline & Tomivosertib (L20) & $-9.3(0.38)$ & $5.1 \mathrm{E}+06$ & & Ponatinib (L7) & $-3.7(0.40)$ & $1.1 \mathrm{E}+02$ \\
\hline & Sapanisertib (L14) & $-6.3(0.55)$ & $3.6 \mathrm{E}+11$ & & Lisinopril (L22) & $-4.7(0.20)$ & $2.5 \mathrm{E}-02$ \\
\hline & Camostat (L23) & $-2.2(0.28)$ & $3.9 \mathrm{E}+01$ & & Chloramphenicol (L25) & $-3.1(0.33)$ & $8.6 \mathrm{E}+06$ \\
\hline & Nafamostat (L24) & $-4.0(0.36)$ & $1.4 \mathrm{E}+05$ & & ZINC95559591 (L10) & $-2.4(0.34)$ & $1.6 \mathrm{E}+04$ \\
\hline & Lisinopril (L22) & $-1.8(0.39)$ & $6.0 \mathrm{E}-02$ & & & & \\
\hline & Valproic Acid (L6) & $-12.8(0.34)$ & $1.3 \mathrm{E}+10$ & & Tomivosertib (L20) & $-13.7(0.27)$ & $5.5 \mathrm{E}+04$ \\
\hline & 4LY1-20Y & $-11.4(0.38)$ & $5.1 \mathrm{E}+11$ & & Tigecycline (L26) & $-7.4(0.29)$ & $1.8 \mathrm{E}+04$ \\
\hline & 6WBZ-TV7 & $-7.2(0.52)$ & $2.7 \mathrm{E}+05$ & & Camostat (L23) & $-7.1(0.38)$ & $2.7 \mathrm{E}+03$ \\
\hline & 4E2RCat (L19) & $-12.0(0.18)$ & $2.6 \mathrm{E}+13$ & & Lisinopril (L22) & $-11.5(0.55)$ & $4.8 \mathrm{E}+09$ \\
\hline U̦ & Linezolid (L27) & $-11.0(0.44)$ & $5.3 \mathrm{E}+16$ & $\underline{v}$ & Nafamostat (L24) & $-7.6(0.55)$ & $1.9 \mathrm{E}+12$ \\
\hline$\hat{=}$ & Ponatinib (L7) & $-9.6(0.54)$ & $1.6 \mathrm{E}+09$ & Z & Linezolid (L27) & $-7.2(0.37)$ & $1.3 \mathrm{E}+04$ \\
\hline & Pevonedistat (L17) & $-9.0(0.37)$ & $1.4 \mathrm{E}+05$ & & Pevonedistat (L17) & $-7.5(0.44)$ & $1.8 \mathrm{E}+09$ \\
\hline & Nafamostat (L24) & $-13.3(0.45)$ & $4.3 \mathrm{E}+08$ & & ZINC95559591 (L10) & $-7.0(0.33)$ & $1.1 \mathrm{E}+06$ \\
\hline & XL413 (L8) & $-7.8(0.44)$ & $1.3 \mathrm{E}+05$ & & ABBV-744 (L11) & $-6.9(0.55)$ & $1.9 \mathrm{E}+07$ \\
\hline & & & & & Zotatifin (L16) & $-10.0(0.40)$ & $1.2 \mathrm{E}+03$ \\
\hline & Azacitidine (L9) & $-4.0(0.46)$ & $2.4 \mathrm{E}+09$ & & Azacitidine (L9) & $-6.9(0.53)$ & $2.6 \mathrm{E}+12$ \\
\hline & XL413 (L8) & $-6.9(0.33)$ & $5.8 \mathrm{E}+01$ & & XL413 (L8) & $-4.2(0.39)$ & $1.1 \mathrm{E}+00$ \\
\hline & Tigecycline (L26) & $-10.9(0.28)$ & $2.7 \mathrm{E}+05$ & & ABBV-744 (L11) & $-4.8(0.35)$ & $5.8 \mathrm{E}+07$ \\
\hline & Camostat (L23) & $-6.0(0.27)$ & $2.9 \mathrm{E}+06$ & & Tigecycline (L26) & $-7.1(0.46)$ & $3.4 \mathrm{E}+15$ \\
\hline & Nafamostat (L24) & $-5.1(0.36)$ & $6.6 \mathrm{E}+03$ & & Nafamostat (L24) & $-5.2(0.34)$ & $2.34 \mathrm{E}+02$ \\
\hline & Chloramphenicol (L25) & $-2.5(0.28)$ & $9.4 \mathrm{E}-04$ & & Ponatinib (L7) & $-6.0(0.56)$ & $2.4 \mathrm{E}+07$ \\
\hline$I$ & ABBV-744 (L11) & $-2.5(0.23)$ & $2.20 \mathrm{E}+06$ & $\stackrel{1}{1}$ & Lisinopril (L22) & $-7.3(0.48)$ & $4.7 \mathrm{E}+10$ \\
\hline$\sum$ & Pevonedistat (L17) & $-3.3(0.37)$ & $6.7 \mathrm{E}+01$ & $\sum$ & ZINC95559591 (L10) & $-5.3(0.50)$ & $2.1 \mathrm{E}+11$ \\
\hline 盲 & JQ1 (L1) & $-4.5(0.30)$ & 4.0E-02 & 竞 & Camostat (L23) & $-4.6(0.37)$ & $5.6 \mathrm{E}+00$ \\
\hline & Ponatinib (L7) & $-3.5(0.32)$ & $2.2 \mathrm{E}+09$ & & 4E2RCat (L19) & $-3.1(0.45)$ & $1.7 \mathrm{E}+02$ \\
\hline & ZINC95559691 & $-6.0(0.18)$ & $1.6 \mathrm{E}+04$ & & Verdinexor (L28) & $-9.5(0.49)$ & $4.8 \mathrm{E}+08$ \\
\hline & 4E2RCat (L19) & $-5.2(0.34)$ & $6.1 \mathrm{E}+09$ & & Pevonedistat (L17) & $-6.0(0.31)$ & $3.5 \mathrm{E}+05$ \\
\hline & CPI-0610 (L13) & $-2.1(0.43)$ & $2.6 \mathrm{E}+01$ & & & & \\
\hline & Tomivosertib (L20) & $-2.0(0.35)$ & $1.2 \mathrm{E}-03$ & & & & \\
\hline & RVX-208 (L2) & $-8.5(0.33)$ & $4.3 \mathrm{E}+06$ & & & & \\
\hline
\end{tabular}

The identified list of drugs with higher free energy barriers shows chemical similarity in a few of the cases. For example, BRD2/BRD4 (PDB: 3ONI/3MXF) domain exhibits a higher binding affinity with JQ1, dBET6 and ABBV-744, where JQ1 is a substructure of dBET6 and hence shows higher chemical similarity. However, unlike BRD2/BRD4, with respect to HDAC2 (PDB: 
4LY1), the control drug $20 \mathrm{Y}$ and Nafamostat, are found to exhibit higher free energy barriers without higher chemical similarity.
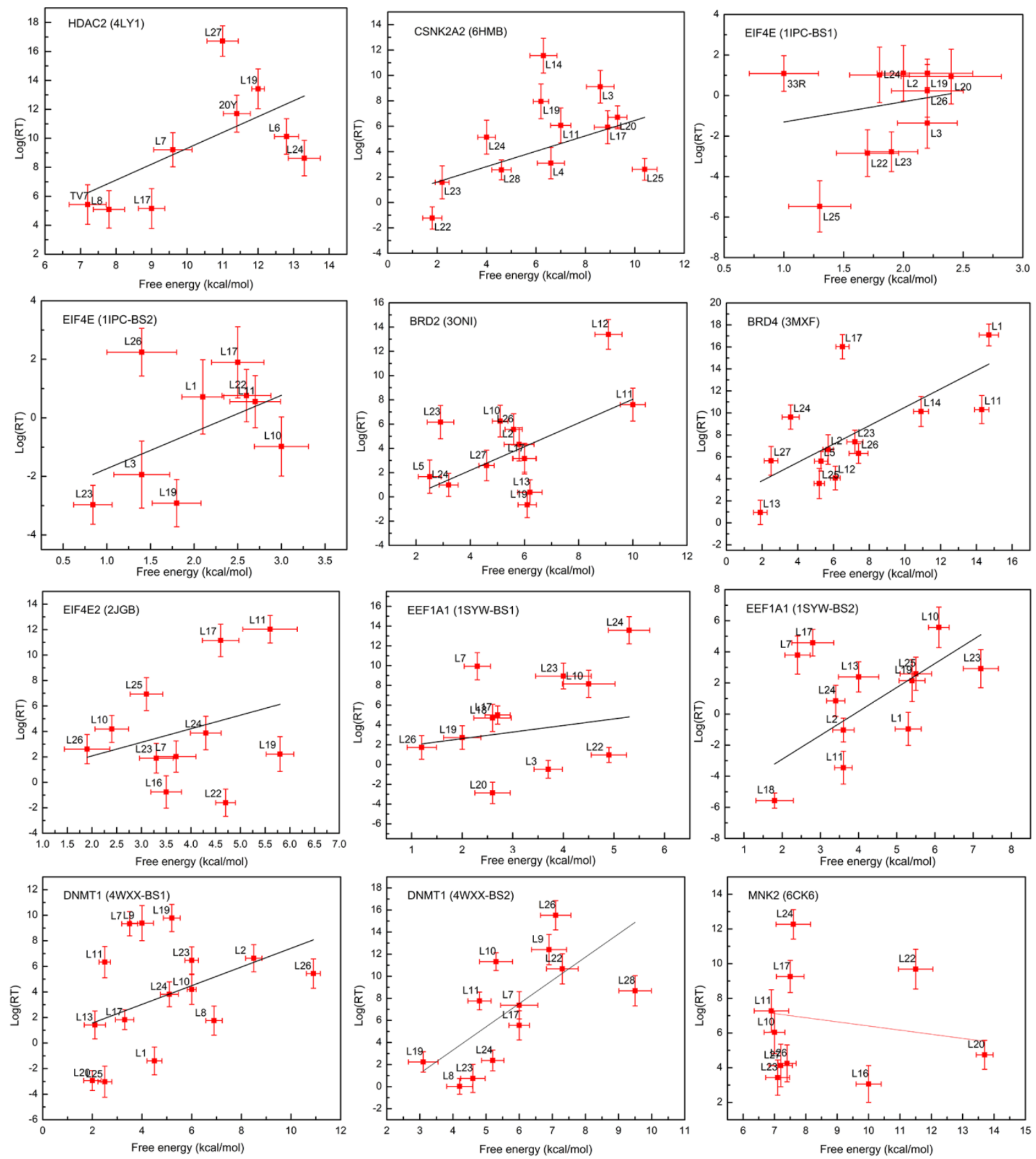

Figure 4. Residence time plots versus free energy barrier for all the systems. 
To corroborate the binding nature evident from free energy barriers, we have also estimated the residence time for the ligands using equations 1 and 2 . The residence time, RT, is calculated for all the 10 replicas, and the resultant average values are reported in Table 2. Most of the cases the estimated RT values are found to be high for the ligands, which have shown higher energy barriers in the FES. Furthermore, the RT values are found to increase linearly with increasing barrier height. This linear correlation is clearly shown in the log (RT) vs. FES barrier data plots in Figure 4. The linear relationship is more clearly shown for the proteins-ligand where the energy barriers are not close. We have also observed that the residence time for the control drugs and previously literature-suggested drugs are found to exhibit higher residence time and free energy barriers. The proteins with inhibitor bound crystal structures, i.e., control drugs (20Y:HDAC2, 4E2RCat:IF4E, Tomivosertib: MNK2, Silmitasertib:CSK22, JQ1:MXF) were found to be in the group of drugs which exhibit higher residence time. It is evident from the interaction energy calculations from docking, $\mathrm{MD}$, and free-energy calculations that these higher residence times correspond to the increase in the protein-drug non-bonded interactions and subsequently confirm the drug's higher stability at the binding site (Figure S5). Thus, in contrast to the prevailing focus on virtual screening of a large number of drugs through molecular docking followed by MM/PBSA binding energy calculations, we propose a multi-target based drug repurposing strategy with robust free energy calculations using enhanced sampling.

\section{Conclusion}

To date, no FDA approved treatment, including vaccines and drugs, has been found for COVID19. However, a range of antivirals and other drugs have shown inhibitory behaviour against SARS-CoV2 in-vitro and in clinical conditions. These drugs either target the viral-related components or the host proteins that regulate the viral pathogenesis. Here, we have performed an 
extensive drug repurposing exercise of the host transcription and translation regulatory proteins for a list of selective drugs that are anticancer compounds, anti-coagulants, antibiotics (bacterial infections), or immunosuppressive in nature. In this study, we report the high throughput analysis of these literature-derived repurposing drug candidates that can be used to target the genetic regulators known to interact with viral proteins based on experimental and interactome studies. On the basis of the known/predictor inhibitor binding sites for these proteins, we extrapolated our multiple protein-multiple ligand approach to identify drugs with approved pharmacological properties that can bind favourably and show higher binding energy as compared to the existing/proposed inhibitors. The molecular docking and simulation analysis revealed that the protein-drug complexes possess stable conformations and differential patterns of interaction energies and hydrogen bonds. It is possible that multiple drugs can bind the same binding site/cavity in a protein with varying binding affinity and interactions. Moreover, we elucidate the difference in the binding energy for these protein-drug complexes using free energy barrier calculations. We must note that in addition to the pre-clinical and FDA approved drugs that target specific regulatory proteins, a range of chemical compounds (Nafamostat, Chloramphenicol, Ponatinib) binds to the other gene transcription and translation regulatory protein with higher affinity and may harbour the potential for therapeutic uses. There is a rapidly growing interest in the development of combination therapy for COVID19 to target multiple enzymes/pathways. Our insilico approach would be envisaged to expedite the process of generating leads for experimental screening for rapid drug repurposing against SARS-CoV2 interacting host proteins. 


\section{ASSOCIATED CONTENT}

\section{Supporting Information.}

Binding sites representation, Average value of interaction energy for different protein-ligand systems, Hydrogen bond details.

The following files are available free of charge.

Protein-ligand conformations corresponding to the FES minimum for article-based, control and identified repurposing drugs.(PDF)

Protein-ligand structures from MD simulation that are used for further FE calculations (PDF)

\section{AUTHOR INFORMATION}

\section{Corresponding Author}

*Sudip Roy (sudip@prescience.in) and *Jayant K. Singh (jayantks@iitk.ac.in)

\section{Author Contributions}

The manuscript was written through contributions of all authors. All authors have given approval to the final version of the manuscript. $\$$ These authors contributed equally.

\section{Notes}

The authors declare no competing financial interests.

\section{ACKNOWLEDGMENT}

A.K. and D.P. thanks IITK for postdoctoral fellowship. JKS would like to acknowledge SERB/DST, India for the partial support. Prescience acknowledges the CSR funding of GST IN. Authors thank IITK for the supercomputing facility. 


\section{REFERENCES}

1. Singh, T. U.; Parida, S.; Lingaraju, M. C.; Kesavan, M.; Kumar, D.; Singh, R. K., Drug repurposing approach to fight COVID-19. Pharmacol Rep 2020, 1-30.

2. Guy, R. K.; DiPaola, R. S.; Romanelli, F.; Dutch, R. E., Rapid repurposing of drugs for COVID-19. Science 2020, 368, 829.

3. Zhou, Y.; Wang, F.; Tang, J.; Nussinov, R.; Cheng, F., Artificial intelligence in COVID19 drug repurposing. The Lancet Digital Health.

4. Trezza, A.; Iovinelli, D.; Santucci, A.; Prischi, F.; Spiga, O., An integrated drug repurposing strategy for the rapid identification of potential SARS-CoV-2 viral inhibitors. Scientific Reports 2020, 10, 13866.

5. Tharappel, A. M.; Samrat, S. K.; Li, Z.; Li, H., Targeting Crucial Host Factors of SARSCoV-2. ACS Infectious Diseases 2020, 6, 2844-2865.

6. Cao, L.; Goreshnik, I.; Coventry, B.; Case, J. B.; Miller, L.; Kozodoy, L.; Chen, R. E.; Carter, L.; Walls, A. C.; Park, Y.-J.; Strauch, E.-M.; Stewart, L.; Diamond, M. S.; Veesler, D.; Baker, D., De novo design of picomolar SARS-CoV-2 miniprotein inhibitors. Science 2020, 370, 426.

7. Menéndez, C. A.; Byléhn, F.; Perez-Lemus, G. R.; Alvarado, W.; de Pablo, J. J., Molecular characterization of ebselen binding activity to SARS-CoV-2 main protease. Science Advances 2020, 6, eabd0345.

8. $\quad$ Sacco, M. D.; Ma, C.; Lagarias, P.; Gao, A.; Townsend, J. A.; Meng, X.; Dube, P.; Zhang, X.; Hu, Y.; Kitamura, N.; Hurst, B.; Tarbet, B.; Marty, M. T.; Kolocouris, A.; Xiang, Y.; Chen, Y.; Wang, J., Structure and inhibition of the SARS-CoV-2 main protease reveals strategy for developing dual inhibitors against M\&lt;sup\&gt;pro\&lt;/sup\&gt; and cathepsin L. Science Advances 2020, eabe 0751 .

9. Mandala, V. S.; McKay, M. J.; Shcherbakov, A. A.; Dregni, A. J.; Kolocouris, A.; Hong, M., Structure and drug binding of the SARS-CoV-2 envelope protein transmembrane domain in lipid bilayers. Nature Structural \& Molecular Biology 2020.

10. Pardo, J.; Shukla, A. M.; Chamarthi, G.; Gupte, A., The journey of remdesivir: from Ebola to COVID-19. Drugs Context 2020, 9, 2020-4-14.

11. Abdelrahman, Z.; Li, M.; Wang, X., Comparative Review of SARS-CoV-2, SARS-CoV, MERS-CoV, and Influenza A Respiratory Viruses. Frontiers in Immunology 2020, 11, 2309.

12. Gordon, D. E.; Hiatt, J.; Bouhaddou, M.; Rezelj, V. V.; Ulferts, S.; Braberg, H.; Jureka, A. S.; Obernier, K.; Guo, J. Z.; Batra, J.; Kaake, R. M.; Weckstein, A. R.; Owens, T. W.; Gupta, M.; Pourmal, S.; Titus, E. W.; Cakir, M.; Soucheray, M.; McGregor, M.; Cakir, Z.; Jang, G.; O’Meara, M. J.; Tummino, T. A.; Zhang, Z.; Foussard, H.; Rojc, A.; Zhou, Y.; Kuchenov, D.; Hüttenhain, R.; Xu, J.; Eckhardt, M.; Swaney, D. L.; Fabius, J. M.; Ummadi, M.; Tutuncuoglu, B.; Rathore, U.; Modak, M.; Haas, P.; Haas, K. M.; Naing, Z. Z. C.; Pulido, E. H.; Shi, Y.; Barrio-Hernandez, I.; Memon, D.; Petsalaki, E.; Dunham, A.; Marrero, M. C.; Burke, D.; Koh, C.; Vallet, T.; Silvas, J. A.; Azumaya, C. M.; Billesbølle, C.; Brilot, A. F.; Campbell, M. G.; Diallo, A.; Dickinson, M. S.; Diwanji, D.; Herrera, N.; Hoppe, N.; Kratochvil, H. T.; Liu, Y.; Merz, G. E.; Moritz, M.; Nguyen, H. C.; Nowotny, C.; Puchades, C.; Rizo, A. N.; SchulzeGahmen, U.; Smith, A. M.; Sun, M.; Young, I. D.; Zhao, J.; Asarnow, D.; Biel, J.; Bowen, A.; Braxton, J. R.; Chen, J.; Chio, C. M.; Chio, U. S.; Deshpande, I.; Doan, L.; Faust, B.; Flores, S.; Jin, M.; Kim, K.; Lam, V. L.; Li, F.; Li, J.; Li, Y.-L.; Li, Y.; Liu, X.; Lo, M.; Lopez, K. E.; Melo, A. A.; Moss, F. R.; Nguyen, P.; Paulino, J.; Pawar, K. I.; Peters, J. K.; Pospiech, T. H.; Safari, 
M.; Sangwan, S.; Schaefer, K.; Thomas, P. V.; Thwin, A. C.; Trenker, R.; Tse, E.; Tsui, T. K. M.; Wang, F.; Whitis, N.; Yu, Z.; Zhang, K.; Zhang, Y.; Zhou, F.; Saltzberg, D.; Hodder, A. J.; Shun-Shion, A. S.; Williams, D. M.; White, K. M.; Rosales, R.; Kehrer, T.; Miorin, L.; Moreno, E.; Patel, A. H.; Rihn, S.; Khalid, M. M.; Vallejo-Gracia, A.; Fozouni, P.; Simoneau, C. R.; Roth, T. L.; Wu, D.; Karim, M. A.; Ghoussaini, M.; Dunham, I.; Berardi, F.; Weigang, S.; Chazal, M.; Park, J.; Logue, J.; McGrath, M.; Weston, S.; Haupt, R.; Hastie, C. J.; Elliott, M.; Brown, F.; Burness, K. A.; Reid, E.; Dorward, M.; Johnson, C.; Wilkinson, S. G.; Geyer, A.; Giesel, D. M.; Baillie, C.; Raggett, S.; Leech, H.; Toth, R.; Goodman, N.; Keough, K. C.; Lind, A. L.; Klesh, R. J.; Hemphill, K. R.; Carlson-Stevermer, J.; Oki, J.; Holden, K.; Maures, T.; Pollard, K. S.; Sali, A.; Agard, D. A.; Cheng, Y.; Fraser, J. S.; Frost, A.; Jura, N.; Kortemme, T.; Manglik, A.; Southworth, D. R.; Stroud, R. M.; Alessi, D. R.; Davies, P.; Frieman, M. B.; Ideker, T.; Abate, C.; Jouvenet, N.; Kochs, G.; Shoichet, B.; Ott, M.; Palmarini, M.; Shokat, K. M.; García-Sastre, A.; Rassen, J. A.; Grosse, R.; Rosenberg, O. S.; Verba, K. A.; Basler, C. F.; Vignuzzi, M.; Peden, A. A.; Beltrao, P.; Krogan, N. J., Comparative host-coronavirus protein interaction networks reveal pan-viral disease mechanisms. Science 2020, eabe9403.

13. Plante, J. A.; Liu, Y.; Liu, J.; Xia, H.; Johnson, B. A.; Lokugamage, K. G.; Zhang, X.; Muruato, A. E.; Zou, J.; Fontes-Garfias, C. R.; Mirchandani, D.; Scharton, D.; Bilello, J. P.; Ku, Z.; An, Z.; Kalveram, B.; Freiberg, A. N.; Menachery, V. D.; Xie, X.; Plante, K. S.; Weaver, S. C.; Shi, P.-Y., Spike mutation D614G alters SARS-CoV-2 fitness. Nature 2020.

14. Ahmed, S. S. S. J.; Paramasivam, P.; Raj, K.; Kumar, V.; Murugesan, R.; Ramakrishnan, V., Regulatory Cross Talk Between SARS-CoV-2 Receptor Binding and Replication Machinery in the Human Host. Frontiers in Physiology 2020, 11, 802.

15. Li, J.; Guo, M.; Tian, X.; Wang, X.; Yang, X.; Wu, P.; Liu, C.; Xiao, Z.; Qu, Y.; Yin, Y.; Wang, C.; Zhang, Y.; Zhu, Z.; Liu, Z.; Peng, C.; Zhu, T.; Liang, Q., Virus-Host Interactome and Proteomic Survey Reveal Potential Virulence Factors Influencing SARS-CoV-2 Pathogenesis. Med.

16. Zhou, Y.; Hou, Y.; Shen, J.; Huang, Y.; Martin, W.; Cheng, F., Network-based drug repurposing for novel coronavirus 2019-nCoV/SARS-CoV-2. Cell Discovery 2020, 6, 14.

17. Gordon, D. E.; Jang, G. M.; Bouhaddou, M.; Xu, J.; Obernier, K.; White, K. M.; O’Meara, M. J.; Rezelj, V. V.; Guo, J. Z.; Swaney, D. L.; Tummino, T. A.; Hüttenhain, R.; Kaake, R. M.; Richards, A. L.; Tutuncuoglu, B.; Foussard, H.; Batra, J.; Haas, K.; Modak, M.; Kim, M.; Haas, P.; Polacco, B. J.; Braberg, H.; Fabius, J. M.; Eckhardt, M.; Soucheray, M.; Bennett, M. J.; Cakir, M.; McGregor, M. J.; Li, Q.; Meyer, B.; Roesch, F.; Vallet, T.; Mac Kain, A.; Miorin, L.; Moreno, E.; Naing, Z. Z. C.; Zhou, Y.; Peng, S.; Shi, Y.; Zhang, Z.; Shen, W.; Kirby, I. T.; Melnyk, J. E.; Chorba, J. S.; Lou, K.; Dai, S. A.; Barrio-Hernandez, I.; Memon, D.; Hernandez-Armenta, C.; Lyu, J.; Mathy, C. J. P.; Perica, T.; Pilla, K. B.; Ganesan, S. J.; Saltzberg, D. J.; Rakesh, R.; Liu, X.; Rosenthal, S. B.; Calviello, L.; Venkataramanan, S.; LiboyLugo, J.; Lin, Y.; Huang, X.-P.; Liu, Y.; Wankowicz, S. A.; Bohn, M.; Safari, M.; Ugur, F. S.; Koh, C.; Savar, N. S.; Tran, Q. D.; Shengjuler, D.; Fletcher, S. J.; O’Neal, M. C.; Cai, Y.; Chang, J. C. J.; Broadhurst, D. J.; Klippsten, S.; Sharp, P. P.; Wenzell, N. A.; Kuzuoglu-Ozturk, D.; Wang, H.-Y.; Trenker, R.; Young, J. M.; Cavero, D. A.; Hiatt, J.; Roth, T. L.; Rathore, U.; Subramanian, A.; Noack, J.; Hubert, M.; Stroud, R. M.; Frankel, A. D.; Rosenberg, O. S.; Verba, K. A.; Agard, D. A.; Ott, M.; Emerman, M.; Jura, N.; von Zastrow, M.; Verdin, E.; Ashworth, A.; Schwartz, O.; d'Enfert, C.; Mukherjee, S.; Jacobson, M.; Malik, H. S.; Fujimori, D. G.; Ideker, T.; Craik, C. S.; Floor, S. N.; Fraser, J. S.; Gross, J. D.; Sali, A.; Roth, B. L.; Ruggero, D.; Taunton, J.; Kortemme, T.; Beltrao, P.; Vignuzzi, M.; García-Sastre, A.; Shokat, K. M.; 
Shoichet, B. K.; Krogan, N. J., A SARS-CoV-2 protein interaction map reveals targets for drug repurposing. Nature 2020, 583, 459-468.

18. V'kovski, P.; Kratzel, A.; Steiner, S.; Stalder, H.; Thiel, V., Coronavirus biology and replication: implications for SARS-CoV-2. Nature Reviews Microbiology 2020.

19. Poduri, R.; Joshi, G.; Jagadeesh, G., Drugs targeting various stages of the SARS-CoV-2 life cycle: Exploring promising drugs for the treatment of Covid-19. Cellular Signalling 2020, 74, 109721.

20. Filippakopoulos, P.; Qi, J.; Picaud, S.; Shen, Y.; Smith, W. B.; Fedorov, O.; Morse, E. M.; Keates, T.; Hickman, T. T.; Felletar, I.; Philpott, M.; Munro, S.; McKeown, M. R.; Wang, Y.; Christie, A. L.; West, N.; Cameron, M. J.; Schwartz, B.; Heightman, T. D.; La Thangue, N.; French, C. A.; Wiest, O.; Kung, A. L.; Knapp, S.; Bradner, J. E., Selective inhibition of BET bromodomains. Nature 2010, 468, 1067-1073.

21. Reich, S. H.; Sprengeler, P. A.; Chiang, G. G.; Appleman, J. R.; Chen, J.; Clarine, J.; Eam, B.; Ernst, J. T.; Han, Q.; Goel, V. K.; Han, E. Z. R.; Huang, V.; Hung, I. N. J.; Jemison, A.; Jessen, K. A.; Molter, J.; Murphy, D.; Neal, M.; Parker, G. S.; Shaghafi, M.; Sperry, S.;

Staunton, J.; Stumpf, C. R.; Thompson, P. A.; Tran, C.; Webber, S. E.; Wegerski, C. J.; Zheng, H.; Webster, K. R., Structure-based Design of Pyridone-Aminal eFT508 Targeting Dysregulated Translation by Selective Mitogen-activated Protein Kinase Interacting Kinases 1 and 2 (MNK1/2) Inhibition. Journal of Medicinal Chemistry 2018, 61, 3516-3540.

22. Pierre, F.; Chua, P. C.; O'Brien, S. E.; Siddiqui-Jain, A.; Bourbon, P.; Haddach, M.; Michaux, J.; Nagasawa, J.; Schwaebe, M. K.; Stefan, E.; Vialettes, A.; Whitten, J. P.; Chen, T. K.; Darjania, L.; Stansfield, R.; Anderes, K.; Bliesath, J.; Drygin, D.; Ho, C.; Omori, M.; Proffitt, C.; Streiner, N.; Trent, K.; Rice, W. G.; Ryckman, D. M., Discovery and SAR of 5-(3chlorophenylamino)benzo[c][2,6]naphthyridine-8-carboxylic acid (CX-4945), the first clinical stage inhibitor of protein kinase CK2 for the treatment of cancer. Journal of medicinal chemistry 2011, 54, 635-654.

23. Schäfer, A.; Baric, R. S., Epigenetic Landscape during Coronavirus Infection. Pathogens 2017, 6,8 .

24. Tutuncuoglu, B.; Cakir, M.; Batra, J.; Bouhaddou, M.; Eckhardt, M.; Gordon, D. E.; Krogan, N. J., The Landscape of Human Cancer Proteins Targeted by SARS-CoV-2. Cancer Discovery 2020, 10, 916.

25. Soukarieh, F.; Nowicki, M. W.; Bastide, A.; Pöyry, T.; Jones, C.; Dudek, K.; Patwardhan, G.; Meullenet, F.; Oldham, N. J.; Walkinshaw, M. D.; Willis, A. E.; Fischer, P. M., Design of nucleotide-mimetic and non-nucleotide inhibitors of the translation initiation factor eIF4E: Synthesis, structural and functional characterisation. European Journal of Medicinal Chemistry 2016, 124, 200-217.

26. Tang, Y.; Liu, J.; Zhang, D.; Xu, Z.; Ji, J.; Wen, C., Cytokine Storm in COVID-19: The Current Evidence and Treatment Strategies. Frontiers in immunology 2020, 11, 1708-1708.

27. Mehta, P.; McAuley, D. F.; Brown, M.; Sanchez, E.; Tattersall, R. S.; Manson, J. J.;

Collaboration, H. A. S., COVID-19: consider cytokine storm syndromes and immunosuppression. Lancet (London, England) 2020, 395, 1033.

28. El Bairi, K.; Trapani, D.; Petrillo, A.; Le Page, C.; Zbakh, H.; Daniele, B.; Belbaraka, R.; Curigliano, G.; Afqir, S., Repurposing anticancer drugs for the management of COVID-19. European Journal of Cancer 2020, 141, 40-61.

29. Saini, K. S.; Lanza, C.; Romano, M.; de Azambuja, E.; Cortes, J.; de las Heras, B.; de Castro, J.; Lamba Saini, M.; Loibl, S.; Curigliano, G.; Twelves, C.; Leone, M.; Patnaik, M. M., 
Repurposing anticancer drugs for COVID-19-induced inflammation, immune dysfunction, and coagulopathy. British Journal of Cancer 2020, 123, 694-697.

30. Liu, B.; Li, M.; Zhou, Z.; Guan, X.; Xiang, Y., Can we use interleukin-6 (IL-6) blockade for coronavirus disease 2019 (COVID-19)-induced cytokine release syndrome (CRS)? Journal of Autoimmunity 2020, 102452.

31. Wilcken, R.; Zimmermann, M. O.; Lange, A.; Joerger, A. C.; Boeckler, F. M., Principles and Applications of Halogen Bonding in Medicinal Chemistry and Chemical Biology. Journal of Medicinal Chemistry 2013, 56, 1363-1388.

32. Marcelo Zaldini, H.; Suellen Melo, T. C.; Diogo Rodrigo, M. M.; Walter Filgueira de Azevedo, J.; Ana Cristina Lima, L., Halogen Atoms in the Modern Medicinal Chemistry: Hints for the Drug Design. Current Drug Targets 2010, 11, 303-314.

33. Pennington, L. D.; Moustakas, D. T., The Necessary Nitrogen Atom: A Versatile HighImpact Design Element for Multiparameter Optimization. Journal of Medicinal Chemistry 2017, 60, 3552-3579.

34. Sadanandam, N.; Debabrata, P.; Mohd Aamir, K.; Sudip, R.; Jayant, S., Potential Drug Candidates for SARS-CoV-2 Using Computational Screening and Enhanced Sampling Methods. ChemRxiv 2020.

35. Morris, G. M.; Huey, R.; Lindstrom, W.; Sanner, M. F.; Belew, R. K.; Goodsell, D. S.; Olson, A. J., AutoDock4 and AutoDockTools4: Automated docking with selective receptor flexibility. Journal of computational chemistry 2009, 30, 2785-2791.

36. Webb, B.; Sali, A., Comparative Protein Structure Modeling Using MODELLER. Current Protocols in Bioinformatics 2016, 54, 5.6.1-5.6.37.

37. Harris, R.; Olson, A. J.; Goodsell, D. S., Automated prediction of ligand-binding sites in proteins. Proteins: Structure, Function, and Bioinformatics 2008, 70, 1506-1517.

38. Abraham, M. J.; Murtola, T.; Schulz, R.; Páll, S.; Smith, J. C.; Hess, B.; Lindahl, E., GROMACS: High performance molecular simulations through multi-level parallelism from laptops to supercomputers. SoftwareX 2015, 1-2, 19-25.

39. MacKerell, a. D.; Banavali, N.; Foloppe, N., Development and current status of the CHARMM force field for nucleic acids. Biopolymers 2001, 56, 257-65.

40. Zoete, V.; Cuendet, M. A.; Grosdidier, A.; Michielin, O., SwissParam: A fast force field generation tool for small organic molecules. Journal of Computational Chemistry 2011, 32, 2359-2368.

41. Bussi, G.; Donadio, D.; Parrinello, M., Canonical sampling through velocity rescaling. The Journal of Chemical Physics 2007, 126, 014101.

42. Parrinello, M.; Rahman, A., Polymorphic transitions in single crystals: A new molecular dynamics method. Journal of Applied Physics 1981, 52, 7182-7190.

43. Essmann, U.; Perera, L.; Berkowitz, M. L.; Darden, T.; Lee, H.; Pedersen, L. G., A smooth particle mesh Ewald method. The Journal of Chemical Physics 1995, 103, 8577-8593.

44. Hess, B.; Bekker, H.; Berendsen, H. J. C.; Fraaije, J. G. E. M., LINCS: A linear constraint solver for molecular simulations. Journal of Computational Chemistry 1997, 18, 14631472.

45. Barducci, A.; Bussi, G.; Parrinello, M., Well-tempered metadynamics: A smoothly converging and tunable free-energy method. Physical Review Letters 2008, 100, 1-4.

46. Laio, A.; Parrinello, M., Escaping free-energy minima. Proceedings of the National Academy of Sciences 2002, 99, 12562. 